\title{
Glucocorticoids Inhibit Neurogenic Plasma Extravasation and Prevent Virus-potentiated Extravasation in the Rat Trachea
}

\author{
G. Piedimonte, ${ }^{\star}$ D. M. McDonald, ${ }^{\ddagger}$ and J. A. Nadel ${ }^{\$ \|}$ \\ *Cardiovascular Research Institute and Departments of ${ }^{\ddagger}$ Anatomy, ${ }^{\S}$ Medicine, and "Physiology, \\ University of California, San Francisco, California 94143
}

\begin{abstract}
Capsaicin increases the permeability of blood vessels in the rat tracheal mucosa through a mechanism involving the release of tachykinins from sensory nerves. This capsaicin-induced increase in vascular permeability is potentiated by viral infections of the respiratory tract. The present study was done to determine whether this "neurogenic plasma extravasation" can be inhibited by glucocorticoids, to learn the time course of this inhibition, and to determine whether glucocorticoids can prevent the potentiating effect of viral respiratory infections on neurogenic plasma extravasation. Groups of pathogen-free F344 rats were treated with dexamethasone for 2 or 8 h (4 $\mathrm{mg} / \mathrm{kg}$ i.p.) or for 48 or $120 \mathrm{~h}(0.5-4 \mathrm{mg} / \mathrm{kg}$ per d i.p.). Another group of rats was treated with dexamethasone for $120 \mathrm{~h}$ following the intranasal inoculation of Sendai virus. The magnitude of plasma extravasation produced by capsaicin or substance $P$ was assessed after this treatment by using Monastral blue pigment and Evans blue dye as intravascular tracers. We found that dexamethasone reduced, in a dose-dependent fashion, the magnitude of plasma extravasation produced in the rat trachea by capsaicin and substance $P$. Significant inhibition was produced by a dose of dexamethasone as small as $0.5 \mathrm{mg} / \mathrm{kg}$ i.p. The effect of dexamethasone had a latency of several hours and reached a maximum after $2 \mathrm{~d}$ of treatment. Furthermore, dexamethasone prevented the potentiation of neurogenic plasma extravasation usually present after $5 \mathrm{~d}$ of Sendai virus respiratory infection. (J. Clin. Invest. 1990. 86:1409-1415.) Key words: neurogenic inflammation • viral infection • dexamethasone $\bullet$ vascular permeability $\bullet$ capsaicin $\bullet$ tachykinins
\end{abstract}

\section{Introduction}

Stimulation of sensory nerves releases neuropeptides (particularly tachykinins) that increase the permeability of venules of the tracheobronchial microvascular bed, thereby producing plasma extravasation (1). The magnitude of this neurogenic plasma extravasation has been shown to be abnormally large in rats with high serologic titers to common respiratory pathogens (Sendai virus, rat coronavirus, and Mycoplasma pul-

This work has been presented in abstract form and published in 1990 (Clin. Res. 38:160a) and (Am. Rev. Respir. Dis. 141:A182).

Address correspondence to Dr. Jay Nadel, Cardiovascular Research Institute, Box 0130, University of California, San Francisco, CA 94143-0130.

Received for publication 20 December 1989 and in revised form 15 May 1990.

J. Clin. Invest.

(c) The American Society for Clinical Investigation, Inc. 0021-9738/90/11/1409/07 $\$ 2.00$

Volume 86, November 1990, 1409-1415 monis) (2-4). Recently, we reported that rats with acute Sendai virus respiratory infections alone also have a potentiation of neurogenic plasma extravasation (5).

Glucocorticoids are known to suppress the biological effects of several inflammatory mediators (6) and can prevent the mediator-induced increase in tracheal vascular permeability (7). However, contradictory data have been reported about the effects of glucocorticoids on the response of the tracheobronchial microcirculation to neuropeptide mediators: glucocorticoids are reported to decrease (3), have no effect on, or even to potentiate neurogenic plasma extravasation $(8,9)$.

In this study, we investigated whether glucocorticoids inhibit neurogenic plasma extravasation in the trachea of rats. In addition, we sought to learn whether glucocorticoids can prevent virus-induced potentiation of neurogenic plasma extravasation.

To achieve our goals, we pretreated rats with dexamethasone for various periods before giving an intravenous injection of capsaicin, a drug that is known to release peptides from certain types of sensory nerves and thereby evoke neurogenic plasma extravasation (10). We also examined the effect of dexamethasone on the action of exogenous substance $P$, which is thought to be one of the mediators of neurogenic plasma extravasation (11). The effect of dexamethasone on virus-induced potentiation of neurogenic plasma extravasation was examined in rats in which Sendai virus infections were produced by intranasal inoculation (5). Changes in the permeability of the tracheal microvasculature were measured by using two tracers with different properties, Evans blue dye (10) and Monastral blue pigment (1).

Our findings show that dexamethasone reduces plasma extravasation produced in the rat trachea by capsaicin and substance $P$ and prevents the potentiation of neurogenic plasma extravasation associated with Sendai virus respiratory infections.

\section{Methods}

Animals. A total of 122 pathogen-free F344 rats (10-12 wk of age) from Charles River Breeding Laboratories, Inc., Raleigh, NC, were used in this study. At the onset of the experiment, body weight averaged $247 \mathrm{~g}$. To prevent microbial contamination, rats were housed in groups of two or three in autoclaved plastic cages isolated by a filter-top (Micro-Isolator System; Lab Products Inc., Maywood, NJ). These cages were placed inside a laminar flow rack enclosure, and all manipulations (feeding, cage changes, administration of drugs) were conducted inside a Class 100 laminar flow workbench (Stay-Clean; Lab Products Inc.). A separate facility was used for housing rats infected with Sendai virus.

Pretreatment. In the first set of experiments, 27 rats were treated with 10 injections over $5 \mathrm{~d}$ with $0.5,1$, or $4 \mathrm{mg} / \mathrm{kg}$ per d of dexamethasone sodium phosphate (Elkins-Sinn Inc., Cherry Hill, NJ). The first injection was given in the afternoon of the first day, and the last 
injection was given in the morning of the experimental day. On the intervening days, the daily dose was administered in two intraperitoneal injections, the first at 8:00-9:00 a.m. and the second at 5:006:00 p.m.

In the second set of experiments, 22 rats were pretreated with dexamethasone for a period ranging from 2 to $120 \mathrm{~h}$. For the 2-h and the $8-\mathrm{h}$ pretreatment, the dose of dexamethasone $(4 \mathrm{mg} / \mathrm{kg}$ i.p.) was given as a single injection, whereas for the $2-\mathrm{d}$ and $5-\mathrm{d}$ pretreatments, the dose of dexamethasone was given as two daily injections of 2 $\mathrm{mg} / \mathrm{kg}$ each.

In the third set of experiments, six rats inoculated with Sendai virus and six controls inoculated with sterile medium were pretreated for $5 \mathrm{~d}$ with $4 \mathrm{mg} / \mathrm{kg}$ per $\mathrm{d}$ of dexamethasone given as two daily intraperitoneal injections. The first injection of dexamethasone was given $1 \mathrm{~h}$ after the inoculation.

In each of the three experiments, control rats (a total of 61) received $1 \mathrm{ml} / \mathrm{kg}$ i.p. of the vehicle used to dissolve dexamethasone (sodium sulfite anhydrous, $1 \mathrm{mg} / \mathrm{ml}$; sodium citrate anhydrous, $19.4 \mathrm{mg} / \mathrm{ml}$; benzyl alcohol, $1 \% \mathrm{vol} / \mathrm{vol}$; $\mathrm{pH} 7.4$ ) according to the protocol of administration described above.

Inoculation of viral suspensions. Rats were infected with Sendai virus following a procedure described previously $(5,12)$. In brief, 12 rats under light anesthesia (sodium methohexital $50 \mathrm{mg} / \mathrm{kg}$ i.p.) were inoculated by dropping into each nostril $25-\mu \mathrm{l}$ aliquots of a suspension containing $10^{5} \mathrm{TCID}_{50}$ per $\mathrm{ml}(50 \%$ tissue culture infective dose) of Sendai (parainfluenza type I) virus. Another 11 rats were inoculated with sterile medium from the same type of cell cultures used to grow the virus. The rats were inoculated on the day of delivery from the vendors and the experiment was performed $5 \mathrm{~d}$ later. During this period, half of the infected rats and half of the pathogen-free controls were treated with dexamethasone, and the other half received the vehicle of dexamethasone.

Description of the experiments. At the end of the pretreatment period, each rat pretreated with dexamethasone was paired with a rat pretreated with vehicle. Alternating between dexamethasone-pretreated and vehicle-pretreated animals, the rats were anesthetized with sodium methohexital $(60-70 \mathrm{mg} / \mathrm{kg}$ i.p.).

To assess vascular permeability, we used two tracers with different properties: Evans blue dye (3\% solution in $0.9 \% \mathrm{NaCl})$ to measure albumin extravasation and Monastral blue pigment (3\% suspension in $0.9 \% \mathrm{NaCl}$; Sigma Chemical Co., St. Louis, MO) to label abnormally permeable blood vessels. A 1:1 mixture of the two tracers was stirred overnight, sonicated in an ultrasonic cleaner for $5 \mathrm{~min}$, and passed through a $5-\mu \mathrm{m}$ filter (Millipore/Continental Water Systems, Bedford, MA).

Immediately after the injection of the tracers $(30 \mathrm{mg} / \mathrm{kg}$ i.v. of each over $5 \mathrm{~s}$ ), neurogenic plasma extravasation was produced by giving an intravenous injection of capsaicin $(75,100$, or $150 \mu \mathrm{g} / \mathrm{kg}$ over $2 \mathrm{~min}$; Sigma Chemical Co.), dissolved in a vehicle having a final concentration of $0.75 \%$ ethanol, $0.375 \%$ Tween 80 , and $0.85 \% \mathrm{NaCl}$ in aqueous solution. A group of 10 rats received only the vehicle used to dissolve the capsaicin $(1 \mathrm{ml} / \mathrm{kg}$ i.v.) to quantify the amount of extravasation of the tracers in the absence of neurogenic inflammation (baseline extravasation). Another 10 rats received an injection of substance $P(5 \mu \mathrm{g} / \mathrm{kg}$ i.v. over $20 \mathrm{~s}$; Peninsula Laboratories, Inc., Belmont, CA) dissolved in $5 \mathrm{mM}$ acetic acid containing $0.9 \% \mathrm{NaCl}$.

5 min after the injection of the tracers, the chest was opened, a cannula was inserted into the ascending aorta through the left ventricle, and the circulation was perfused for $2 \mathrm{~min}$ with fixative ( $1 \%$ paraformaldehyde in $50 \mathrm{mM}$ citrate buffer, $\mathrm{pH} \mathrm{3.5)}$ at a pressure of 120 $\mathrm{mmHg}$. The four rostral-most tracheal rings were removed, further fixed in $3 \%$ glutaraldehyde, and embedded in glycol methacrylate. Sections $3 \mu \mathrm{m}$ in thickness were stained with toluidine blue and Alcian blue/periodic acid Schiff for the morphological analysis of the airway mucosa. The segment of trachea from the fifth cartilaginous ring to the carina, cleaned of connective tissue and opened along the ventral midline, was blotted with bibulous paper, weighed, and incubated in $3 \mathrm{ml}$ of $1 \%$ sodium Suramin in methanol (FBA Pharmaceuticals, Division of Mobay Chemical Corp., New York) to extract the extravasated Evans blue dye (13). After $4 \mathrm{~d}$ of incubation at room temperature, tracheas were removed from the Suramin, washed overnight in methanol and then prepared as whole mounts following a procedure described previously (1).

Measurement of vascular permeability. The extravasation of Evans blue-labeled macromolecules from the tracheal microcirculation was quantified by measuring the optical density of the Suramin extracts at a wavelength of $620 \mathrm{~nm}$. The amount of Evans blue dye extravasated in the trachea, expressed in nanograms per milligram of wet weight, was interpolated from a standard curve of Evans blue concentrations $(0.5$ to $10 \mu \mathrm{g} / \mathrm{ml})$. After $4 \mathrm{~d}$ of incubation in Suramin, virtually all of the Evans blue dye in the specimens was displaced (13), without affecting the distribution of Monastral blue particles trapped within the basal lamina of the abnormally permeable blood vessels. The area density of Monastral blue-labeled vessels was determined by using stereological point counting with a multipurpose test lattice of 51 points spaced at equal intervals $(3,5)$ and was reported as the average of values measured in 20 regions (each measuring $0.2 \mathrm{~mm}^{2}$ in area) located between cartilaginous rings, from ring 5 to ring 25 , on the right side of each tracheal whole mount.

Detection of Sendai virus by indirect immunofluorescence. In the experiments dealing with Sendai virus infections, the left lung was removed aseptically immediately before vascular perfusion and was frozen at $-70^{\circ} \mathrm{C}$ in Hepes-buffered Leibovitz L15 medium containing penicillin $\mathrm{G}(100 \mu \mathrm{g} / \mathrm{ml})$, streptomycin sulfate $(100 \mu \mathrm{g} / \mathrm{ml})$, and amphotericin B $(2.5 \mu \mathrm{g} / \mathrm{ml})$. The lung was thawed and homogenized (Polytron; Brinkmann, Lucerne, Switzerland), and $0.2 \mathrm{ml}$ of this homogenate diluted $1: 10$ in L15 medium was incubated for $1 \mathrm{~h}$ at $37^{\circ} \mathrm{C}$ to elute the virus. This lung suspension was clarified by centrifugation at 2,000 rpm for $30 \mathrm{~min}$, diluted 1:10 in $2 \mathrm{ml}$ of L15 medium, and inoculated in duplicate into Rhesus monkey kidney cell monolayers (Viromed Laboratories, Minneapolis, MN). After $5 \mathrm{~d}$ of incubation at $34^{\circ} \mathrm{C}$, cell monolayers were washed with Dulbecco's phosphate-buffered saline (pH 7.6) and dispersed by using EDTA (0.02\%)-trypsin ( $0.05 \%)$ solution for $5 \mathrm{~min}$ at $34^{\circ} \mathrm{C}$. Cells collected by centrifugation at $1,500 \mathrm{rpm}$ for $15 \mathrm{~min}$ were resuspended in Dulbecco's phosphate-buffered saline, spun by cytocentrifugation ( $800 \mathrm{rpm}$ for $5 \mathrm{~min}$ ) onto glass slides in duplicate, and fixed in acetone at $4^{\circ} \mathrm{C}$ for $10 \mathrm{~min}$. An indirect immunofluorescence assay $(5,12)$ was performed on these preparations using a chicken anti-parainfluenza type I primary antibody and a fluorescein isothiocyanate-labeled sheep anti-chicken immunoglobulin $G$ secondary antibody (Wellcome Diagnostics, Dartford, England). We tested one rat from each cage of animals inoculated with viral suspensions or with sterile medium (a total of five rats per group).

Antibody determinations. A $1-\mathrm{ml}$ blood sample, withdrawn from each rat infected with Sendai virus and from each pathogen-free control immediately before the injection of the tracers, was used for enzyme-linked immunosorbent assays of serum antibody titers to Sendai virus, rat coronavirus, and Mycoplasma pulmonis (Microbiological Associates, Bethesda, MD).

Statistical analysis. All data reported in this study are expressed as the mean \pm standard error of the mean (SEM). Mean values of stereological measurements of Monastral blue extravasation and spectrophotometric measurements of Evans blue extravasation were analyzed by one-way analysis of variance. Pairwise comparisons between means were performed by the Student-Newman-Keuls test (14). The effect of dexamethasone on the baseline amount of extravasation of the tracers was assessed by using the unpaired two-tailed Student's $t$ test. Differences having a $P$ value $<0.05$ were considered significant.

\section{Results}

Changes in body weight and tracheal weight produced by dexamethasone. Rats that did not receive dexamethasone had an average gain in body weight of $6 \pm 1 \%$ over the 5-d experiment, 


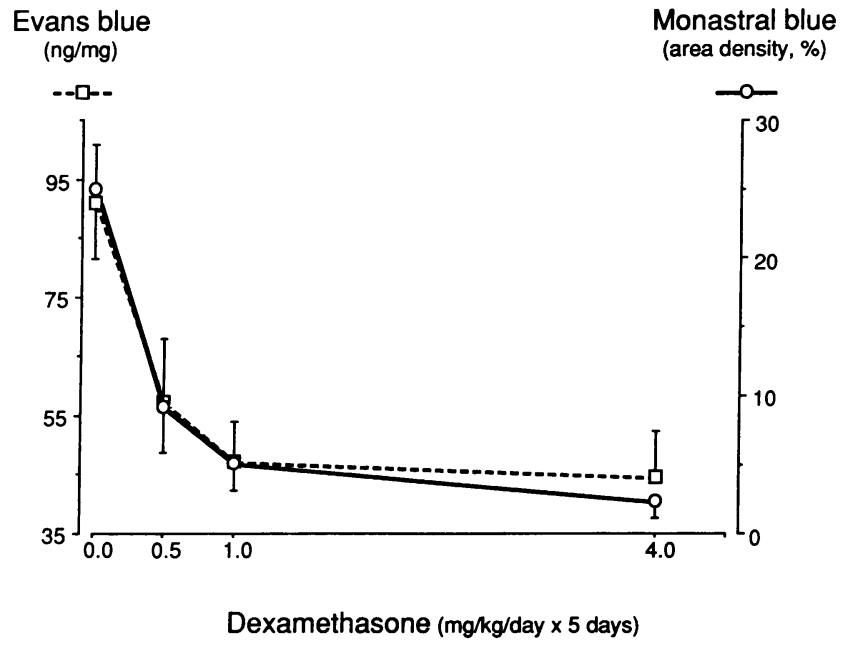

Figure 1. Effect of increasing doses of dexamethasone on neurogenic plasma extravasation produced in the trachea of rats by a high dose of capsaicin $(150 \mu \mathrm{g} / \mathrm{kg}$ i.v.). The control rats received the vehicle of dexamethasone for $5 \mathrm{~d}(0.0 \mathrm{mg} / \mathrm{kg}$ dexamethasone $)$. The dashed line shows the amount of Evans blue extravasation, quantified by spectrophotometry and expressed as ng of dye extracted per $\mathrm{mg}$ of tissue wet weight (left $y$-axis). The continuous line shows the area density of Monastral blue-labeled blood vessels measured in tracheal whole mounts by stereological point counting (right $y$-axis). All three doses of dexamethasone produced a significant reduction in the amount of extravasation of both tracers $(P<0.01)$. Values are means \pm SEM; $n$, 5 or 6 rats per group.

whereas rats pretreated with $0.5,1$, or $4 \mathrm{mg} / \mathrm{kg}$ per $\mathrm{d}$ of dexamethasone had a loss in body weight (respectively $8 \pm 1 \%$, $10 \pm 1 \%, 14 \pm 2 \%$ ). Rats having shorter periods of pretreatment ( $2 \mathrm{~h}$ to $2 \mathrm{~d}$ ) remained within $3 \%$ of their initial body weight. Similarly, $5 \mathrm{~d}$ of dexamethasone pretreatment caused an average reduction of $10 \pm 2 \%$ in tracheal wet weight compared to untreated controls, whereas no difference was found after $2 \mathrm{~h}$, $8 \mathrm{~h}$, or $2 \mathrm{~d}$ of pretreatment. $5 \mathrm{~d}$ after the inoculation with Sendai virus, no significant change was found in body weight and tracheal weight compared to pathogen-free controls, either with or without dexamethasone pretreatment.

Baseline amount of extravasation in the absence of capsaicin. After $5 \mathrm{~d}$ of dexamethasone, rats that received an injection of vehicle (no capsaicin) had slightly more extravasated Evans blue dye in their tracheas $(34.9 \pm 4.9 \mathrm{ng}$ of dye per $\mathrm{mg}$ of tissue wet weight) than did the controls not pretreated with dexa- methasone $(29.5 \pm 2.2 \mathrm{ng} / \mathrm{mg})$, but this difference was not statistically significant $(P=0.35 ; n=5$ per group). No Monastral blue-labeled blood vessels were found in the trachea in the absence of capsaicin-induced neurogenic inflammation.

Effect of dexamethasone on plasma extravasation induced by capsaicin and by substance $P$ in pathogen-free rats. The increase in the permeability of blood vessels produced in the trachea of pathogen-free rats by a large dose of capsaicin (150 $\mu \mathrm{g} / \mathrm{kg}$ ) was diminished by $5 \mathrm{~d}$ of pretreatment with dexamethasone in a dose-dependent fashion (Fig. 1). Both the area density of Monastral blue-labeled vessels and the amount of extravasated Evans blue-labeled macromolecules were significantly reduced by doses of dexamethasone as low as $0.5 \mathrm{mg} / \mathrm{kg}$ per d $(P<0.01)$.

In control rats, a lower dose of capsaicin $(100 \mu \mathrm{g} / \mathrm{kg})$ produced a smaller but still significant amount of extravasation of Monastral blue $(P<0.01$; Fig. 2 , left $)$ and Evans blue $(P$ $<0.05$; Fig. 2, right). However, in rats pretreated for $5 \mathrm{~d}$ with 0.5 or $1 \mathrm{mg} / \mathrm{kg}$ per d of dexamethasone, this dose of capsaicin did not produce a significant increase in vascular permeability.

Dexamethasone ( $4 \mathrm{mg} / \mathrm{kg}$ per $\mathrm{d}$ for $5 \mathrm{~d}$ ) also reduced significantly Monastral blue extravasation $(6.0 \pm 1.8 \%$ vs. $15.8 \pm 1.9 \%$ area density; $P<0.05 ; n=5$ rats per group) and Evans blue extravasation $(50.2 \pm 5.6 \mathrm{ng} / \mathrm{mg}$ vs. $66.1 \pm 4.8 \mathrm{ng} / \mathrm{mg} ; P<0.05)$ produced by an intravenous injection of substance $P(5 \mu \mathrm{g} / \mathrm{kg})$.

Plasma extravasation produced by capsaicin $(150 \mu \mathrm{g} / \mathrm{kg})$ was not significantly reduced by dexamethasone $(4 \mathrm{mg} / \mathrm{kg})$ administered $2 \mathrm{~h}$ before the injection of capsaicin, compared to that of controls which received only the vehicle of dexamethasone (Fig. 3). However, Monastral blue extravasation was significantly reduced $8 \mathrm{~h}$ after the same dose of dexamethasone $(P<0.01$; Fig. 3 , top $)$, and an even greater inhibition was observed after $2 \mathrm{~d}$ of dexamethasone $(P<0.05)$. After $5 \mathrm{~d}$ of treatment, Monastral blue extravasation was further reduced compared to the 2-d time point, but this difference was not statistically significant. As an indication that the injections themselves did not influence the responsiveness to capsaicin, the area density of Monastral blue-labeled tracheal blood vessels in capsaicin-treated rats that were injected with the vehicle of dexamethasone did not show any significant change over time. Capsaicin-induced extravasation of Evans blue-labeled macromolecules was significantly reduced $8 \mathrm{~h}$ after dexamethasone administration $(P<0.01$; Fig. 3 , bottom $)$. After 2 and 5 d of treatment, Evans blue extravasation was further reduced, but the difference with the previous time point was not statistically significant.

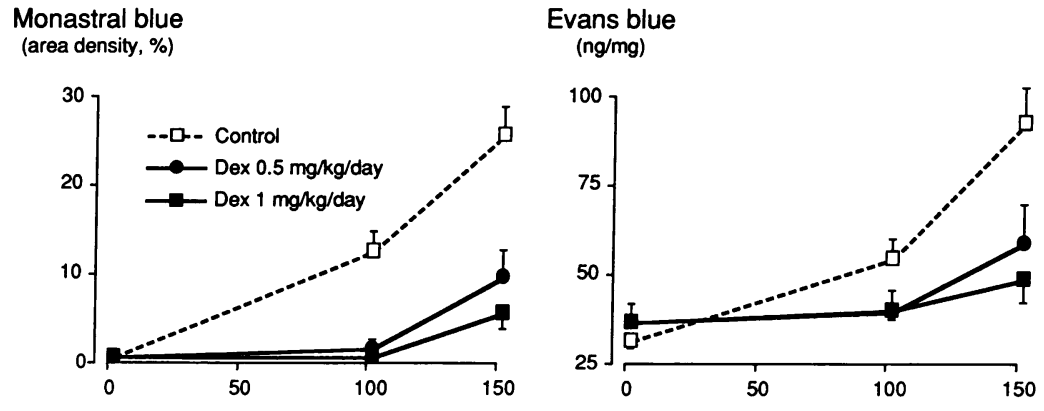

C a p s a c in $(\mu g / k g)$
Figure 2. Amount of neurogenic plasma extravasation (mean \pm SEM) produced by two different doses of capsaicin ( 100 and $150 \mu \mathrm{g} / \mathrm{kg}$ i.v.), or by its vehicle, in the trachea of rats treated for $5 \mathrm{~d}$ with $1 \mathrm{mg} / \mathrm{kg}$ per d dexamethasone (solid squares, $n, 3$ rats), $0.5 \mathrm{mg} / \mathrm{kg}$ per d dexamethasone (solid circles, $n, 3$ rats), or 1 $\mathrm{ml} / \mathrm{kg}$ per $\mathrm{d}$ vehicle (open squares, $n, 6$ rats). Monastral blue extravasation is expressed as the area density of labeled vessels in the tracheal mucosa (left). Spectrophotometric measurements of Evans blue extravasation are expressed as $\mathrm{ng}$ of dye extracted per $\mathrm{mg}$ of tissue wet weight (right). 

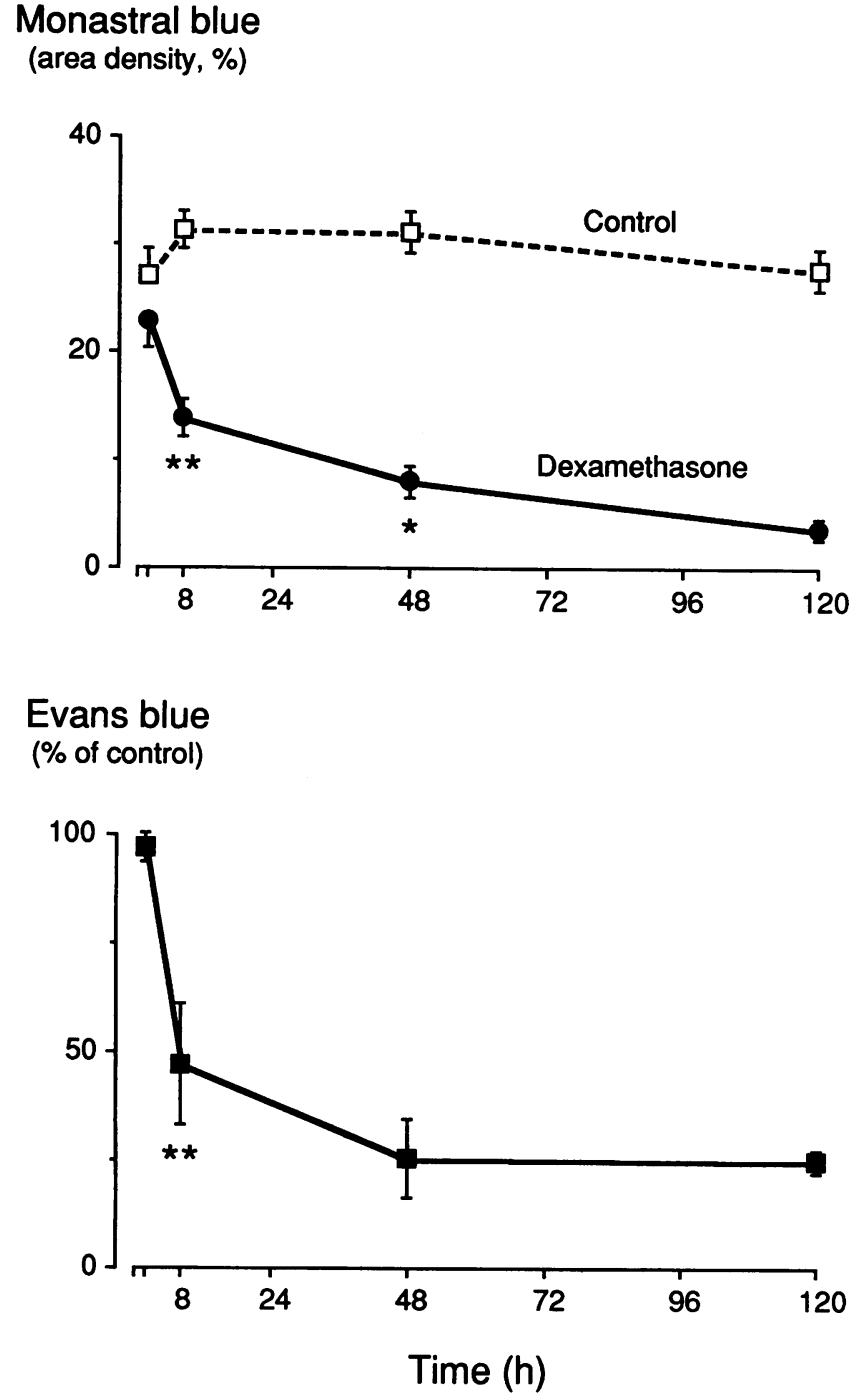

Figure 3. Time course of the inhibitory effect of dexamethasone (4 $\mathrm{mg} / \mathrm{kg}$ per d; see Methods) on Monastral blue (top) and Evans blue (bottom) extravasation from tracheal blood vessels induced by capsaicin $(150 \mu \mathrm{g} / \mathrm{kg}$ i.v.). Monastral blue extravasation in dexamethasonetreated rats (solid circles) and vehicle-treated rats (open squares) is expressed as the area density of labeled blood vessels. The amount of Evans blue extravasation in dexamethasone-treated rats is expressed as a percentage of the paired control values. Values are mean $\pm S E M$; $n, 5$ or 6 rats per group. Asterisks express the statistical significance of the difference with the earlier time point $\left({ }^{*} P<0.05 ;{ }^{* *} P<0.01\right)$.

Effect of dexamethasone on virus-induced potentiation of neurogenic plasma extravasation. Indirect immunofluorescence assays specific for Sendai virus confirmed the presence of the infection in the lungs of each virus-inoculated rat that was tested in this study. None of the pathogen-free controls was found to be infected by Sendai virus. Furthermore, none of these rats had detectable antibody titers to Sendai virus, rat coronavirus, or M. pulmonis.

Neurogenic plasma extravasation was markedly potentiated in the infected rats that did not receive dexamethasone (Fig. 4). In evidence of this potentiation, a threshold dose of

Monastral blue
(area density, \%)

Pathogen-free

(area density, $\%$ )

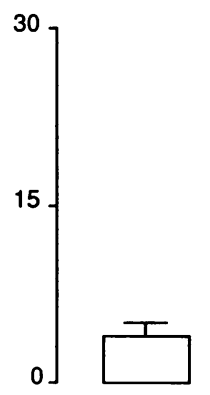
Evans blue
(ng/mg)

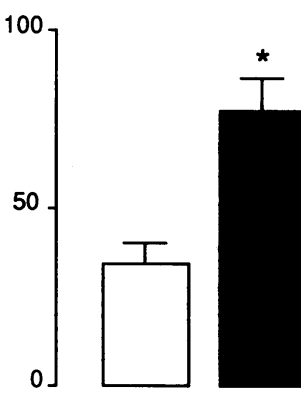

Vehicle

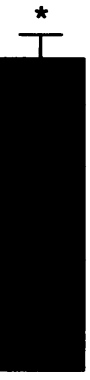

Infected

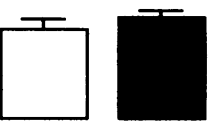

Dexamethasone
Figure 4. Magnitude of Monastral blue (top) and Evans blue (bottom) extravasation in the trachea of pathogen-free rats (open columns) and Sendai virus-infected rats (solid columns) following the injection of a threshold dose of capsaicin (75 $\mu \mathrm{g} / \mathrm{kg}$ i.v.). The infection produced a significant potentiation of neurogenic plasma extravasation, but this effect was prevented by dexamethasone. Values are mean $\pm S E M ; n, 5$ or 6 rats per group. Asterisks express the statistical significance of the difference between infected rats and pathogen-free controls $\left({ }^{*} P<0.01\right)$.

capsaicin $(75 \mu \mathrm{g} / \mathrm{kg})$, which did not produce a detectable increase of vascular permeability in pathogen-free rats, produced a significant increase of both Monastral blue extravasation ( $P$ $<0.01$; Fig. 4, top $)$ and Evans blue extravasation $(P<0.01$; Fig. 4 , bottom) in the rats infected with Sendai virus.

However, twice daily dexamethasone treatment $(4 \mathrm{mg} / \mathrm{kg}$ per d) for $5 \mathrm{~d}$ prevented the Sendai virus-induced potentiation of neurogenic plasma extravasation. After this treatment with dexamethasone, there was no difference in capsaicin-induced Monastral blue or Evans blue extravasation in rats infected with Sendai virus compared to pathogen-free rats.

Morphology of the tracheal mucosa. The tracheas of pathogen-free rats pretreated with dexamethasone were histologically different from vehicle-pretreated controls in several ways. First, consistent with the inhibition of neurogenic plasma extravasation by dexamethasone, there was less edema of the lamina propria and narrower spaces between epithelial cells in the capsaicin-treated rats. Second, there was a reduction in the number of globule leukocytes in the tracheal epithelium, a known effect of dexamethasone (15). Third, there was an abnormally large amount of secretory material accumulated within the epithelial secretory cells of the dexamethasone pre- 
treated rats. In these animals, capsaicin did not produce the expected degranulation of the epithelial secretory cells (3). These histological changes were most conspicuous in rats that received $4 \mathrm{mg} / \mathrm{kg}$ dexamethasone for $5 \mathrm{~d}$.

After $5 \mathrm{~d}$ of Sendai virus infection, the most prominent pathological change in the tracheal mucosa was the presence in the lamina propria of patchy infiltrates of inflammatory cells, mainly lymphocytes and other mononuclear cells. Polymorphonuclear neutrophils were uncommon. In some regions, the epithelium was invaded by inflammatory cells, was disorganized, and contained some degenerating cells. In contrast, the tracheal mucosa of Sendai virus-infected rats that received dexamethasone did not have these conspicuous morphological alterations and resembled the mucosa of dexamethasonetreated pathogen-free controls. In particular, mononuclear cell infiltrates were rare, and the epithelial degenerative changes were not present.

\section{Discussion}

Effect of glucocorticoids on neurogenic plasma extravasation. This study shows that dexamethasone inhibits, in a dose-dependent fashion, the increase of tracheal vascular permeability produced by activating sensory nerves with an intravenous injection of capsaicin. In contrast to some previous studies, marked inhibition was found with doses of dexamethasone within the clinical therapeutic range. Dexamethasone also inhibited the exaggerated vascular responses associated with Sendai virus respiratory infection. Dexamethasone did not diminish the baseline vascular permeability to the tracers used.

Several studies have shown that glucocorticoids inhibit the leakage of macromolecules from postcapillary venules induced by a variety of inflammatory mediators (16-18). However, glucocorticoids have also been reported in previous studies to have no influence, or even to enhance, plasma extravasation induced in the airways by vagus nerve stimulation or by the inhalation of irritants such as cigarette smoke (8) and hydrochloric acid (9), stimuli that are thought to act by activating capsaicin-sensitive sensory nerves. Our data suggest that the latter observations could be due to the dose or timing of glucocorticoid administration or to the fact that the plasma extravasation produced by these irritants could involve mechanisms that are not glucocorticoid-sensitive.

Time course of glucocorticoid inhibition of neurogenic plasma extravasation. We show that the inhibitory effect of dexamethasone on capsaicin-induced extravasation first becomes detectable in more than $2 \mathrm{~h}$ but in less than $8 \mathrm{~h}$ and that maximal inhibition is achieved by $2 \mathrm{~d}$. According to some previous studies, the suppression of responses to other inflammatory stimuli by glucocorticoids was evident sooner than what we observed. For example, Svensjo and Roempke showed by intravital microscopy in hamster cheek pouch preparations that macromolecular leakage produced by bradykinin or histamine is virtually abolished after $2.5 \mathrm{~h}$ of topical glucocorticoid treatment (16). Similarly, Tsurufuji and co-workers found that dexamethasone produces maximal inhibition of serotonin-induced footpad edema in mice $3 \mathrm{~h}$ after subcutaneous administration (17). Like Tsurufuji et al. (17), we found that a delay exists between the time of administration of dexamethasone and the subsequent inhibition of extravasation.
Differences in the exact timing may be related to differences in the sensitivity of the measurements, the specific vascular bed studied, or to differences in the mechanism of dexamethasone-induced inhibition of extravasation produced by various mediators.

Inhibition of virus-induced potentiation of neurogenic plasma extravasation. We have recently shown that the increase in vascular permeability produced by neuropeptides released from sensory nerves is exaggerated in the presence of respiratory infections due to Sendai virus at a time when baseline vascular permeability in the respiratory mucosa is normal (5). Similar findings have been reported in rats with high serologic titers to Sendai virus, rat coronavirus, and Mycoplasma pulmonis (2-4). In this study, we show that the administration of dexamethasone can prevent the potentiation of neurogenic plasma extravasation induced in the trachea by Sendai virus infections. We also found that the inflammatory infiltrates and the epithelial damage associated with this acute viral infection are not present after treatment with dexamethasone. This finding is consistent with the beneficial effects of glucocorticoids on Sendai virus-induced pneumonia in hamsters (19). However, in our study dexamethasone administered after the inoculation of rats with Sendai virus did not prevent the establishment of the viral infection, as shown by indirect immunofluorescence assay.

Possible mechanisms of action of glucocorticoid inhibition of neurogenic extravasation. Corticosteroids are very potent at suppressing various inflammatory responses, but the exact mechanisms are unknown (20). In inflammatory diseases of the airways such as asthma, edema is a prominent feature, and it is suggested that beneficial effects of corticosteroids in this disease are due, at least in part, to the drug's inhibition of plasma extravasation (21). Multiple cells may be involved in the edematogenic response in asthma, and most putative cells have been shown to be affected by corticosteroids (6).

For these reasons, investigators interested in regulation of vascular permeability have examined simpler "models" in animals. We believe that neurogenic plasma extravasation may be an important mechanism for edema formation in inflammatory diseases, and we have shown that neurogenic plasma extravasation is potently inhibited by corticosteroids in therapeutic concentrations. Because dexamethasone reduced the extravasation produced by substance $P$ as well as by capsaicin, it is likely that the inhibition is exerted at sites of action of the released neuropeptides and not exclusively on the release of the neuropeptides from sensory nerves. Because sites of leakage in neurogenic extravasation are in the postcapillary venules, the presumed sites of inhibitory action of glucocorticoids are cells in this structure, the endothelial cells and the pericytes. Both of these cells could be involved in the opening of gaps in the endothelium that occur when increased vascular permeability occurs. For example, contractile elements (22) in the pericytes may provide the force required to open the gaps, and this might be resisted by the production of proteins that maintain adherence of the junctions between endothelial cells. The fact that there is a lag of hours after initiation of corticosteroid therapy and the onset of inhibitory effects on vascular permeability in the present study and in previous studies (16, 17) suggests that the generation of new molecules might be involved. Such an event could involve the generation of adhe- 
sion molecules in the junctions. Alternatively, it could involve the generation of inhibitory proteins that suppress vascular cell contractility (22), as suggested by Tsurufuji and co-workers (17).

In neurogenic inflammatory responses, we suggest an additional possible mechanism of suppressive action of corticosteroids, an effect on expression of an enzyme, neutral endopeptidase (NEP) ${ }^{1}$ in the postcapillary venule. Neutral endopeptidase is a membrane-bound enzyme located on the surface of cells that contain receptors for the neuropeptides (such as substance $P$ ) that are released from the sensory nerves during neurogenic inflammation. This enzyme, by cleaving and thus inactivating the neuropeptides, limits the effect of neurogenic inflammation on various target tissues such as submucosal glands (23), airway smooth muscle (24), neutrophil adhesion (25), and vascular permeability (26): Delivery of exogenous human recombinant NEP suppresses neurogenic inflammatory responses $(27,28)$, presumably by increased inactivation of the responsible neuropeptides. Similarly, we hypothesize that upregulation of NEP on specific cells will decrease their response to neurogenic inflammatory stimuli such as capsaicin.

It has recently been shown that corticosteroids produce a slow induction of NEP activity in cultured human airway epithelial cells (29). In addition, we have found that NEP immunoreactivity exists in the postcapillary venules of rat airways (Nadel, Ueki, and Piedimonte, unpublished observations). Furthermore, inhibition of NEP causes exaggerated neurogenic extravasation (26), and the delivery of exogenous human recombinant NEP further inhibits neurogenic extravasation (28). We propose that NEP upregulation in postcapillary venules by corticosteroids could explain this effect of the drug on neurogenic extravasation. Confirmation of this hypothesis will require further investigation (e.g., in situ hybridization).

In conclusion, the results of this study show that dexamethasone inhibits, in a dose- and time-dependent fashion, the increase of vascular permeability produced in the rat trachea by endogenous and exogenous tachykinins (neurogenic plasma extravasation) and can prevent the potentiation of neurogenic plasma extravasation induced by viral respiratory infections.

\section{Acknowledgments}

The authors thank Patty Snell and Beth Cost for their assistance in preparing the manuscript. They also thank Amy Haskell, Simona Ikeda, and Iris Ueki for their technical assistance.

This study was supported in part by NIH Program Project Grant HL-24136

\section{References}

1. McDonald, D. M. 1988. Neurogenic inflammation in the rat trachea. I. Changes in venules, leucocytes, and epithelial cells. J. Neurocytol. 17:583-603.

2. McDonald, D. M. 1988. Respiratory tract infections increase susceptibility to neurogenic inflammation in the rat trachea. Am. Rev. Respir. Dis. 137:1432-1440.

3. Huang, H.-T., A. Haskell, and D. M. McDonald. 1989. Changes

1. Abbreviations used in this paper: NEP, neutral endopeptidase. in epithelial secretory cells and potentiation of neurogenic inflammation in the trachea of rats with respiratory tract infections. Anat. Embryol. 180:325-341.

4. Borson, D. B., J. J. Brokaw, K. Sekizawa, D. M. McDonald, and J. A. Nadel. 1989. Neutral endopeptidase and neurogenic inflammation in rats with respiratory infections. J. Appl. Physiol. 66:2653-2658.

5. Piedimonte, G., J. A. Nadel, E. Umeno, and D. M. McDonald. 1990. Sendai virus infection potentiates neurogenic inflammation in the rat trachea. J. Appl. Physiol. 68:754-760.

6. Bowen, D. L., and A. S. Fauci. 1988. Adrenal corticosteroids. In Inflammation: Basic Principles and Clinical Correlates. J. I. Gallin, I. M. Goldstein, and R. Snyderman, editors. Raven Press, Ltd., New York. 877-895.

7. Andersson, P. T., and C. G. A. Persson. 1988. Developments in anti-asthma glucocorticoids. In New Anti-Asthma Drugs. Birkhaeuser Verlag, Basel. 239-260.

8. Lundberg, J. M., C.-R. Martling, A. Saria, K. Folkers, and S. Rosell. 1983. Cigarette smoke-induced airway oedema due to activation of capsaicin-sensitive vagal afferents and substance $P$ release. Neuroscience. 10:1361-1368.

9. Martling, C.-R., and J. M. Lundberg. 1988. Capsaicin sensitive afferents contribute to acute airway edema following tracheal instillation of hydrochloric acid or gastric juice in the rat. Anesthesiology. 68:350-356.

10. Saria, A., J. M. Lundberg, G. Skofitsch, and F. Lembeck. 1983. Vascular protein leakage in various tissues induced by substance $P$, capsaicin, bradykinin, serotonin, histamine, and by antigen challenge. Naunyn-Schmiedebergs Arch. Pharmacol. 324:212-218.

11. Lundberg, J. M., A. Saria, E. Brodin, S. Rosell, and K. Folkers. 1983. A substance $P$ antagonist inhibits vagally induced increase in vascular permeability and bronchial smooth muscle contraction in the guinea pig. Proc. Natl. Acad. Sci. USA. 80:1120-1124.

12. Dusser, D. J., D. B. Jacoby, T. D. Djokic, I. Rubinstein, D. B. Borson, and J. A. Nadel. 1989. Virus induces airway hyperresponsiveness to tachykinins: role of neutral endopeptidase. J. Appl. Physiol. 67:1504-1511.

13. Jancso-Gabor, A., J. Szolcsanyi, and N. Jancso. 1967. A simple method for measuring the amount of azovan blue exuded into the skin in response to an inflammatory stimulus. J. Pharm. Pharmacol. 19:486-487.

14. Zar, J. H. 1974. Multiple comparisons. In Biostatistical Analysis. Prentice-Hall, Inc., Englewood Cliffs, NJ. 151-155.

15. Tam, E. K., L. D. Calonico, J. A. Nadel, and D. M. McDonald. 1988. Globule leukocytes and mast cells in the rat trachea: their number, distribution, and response to compound 48/80 and dexamethasone. Anat. Embryol. 178:107-118.

16. Svensjo, E., and K. Roempke. 1985. Time-dependent inhibition of bradykinin- and histamine-induced microvascular permeability increase by local glucocorticoid treatment. Prog. Respir. Res. 19:173-180.

17. Tsurufuji, S., K. Sugio, and F. Takemasa. 1979. The role of glucocorticoid receptor and gene expression in the anti-inflammatory action of dexamethasone. Nature (Lond.). 280:408-410.

18. Bjork, J., T. Goldschmidt, G. Smedegard, and K.-E. Arfors. 1985. Methylprednisolone acts at the endothelial cell level reducing inflammatory responses. Acta Physiol. Scand. 123:221-223.

19. Kimsey, P. B., M. E. Pecquet Goad, Z. Zhi-Bo, G. Brackee, and J. G. Fox. 1989. Methylprednisolone acetate modulation of infection and subsequent pulmonary pathology in hamsters exposed to Parainfluenza-1 virus (Sendai). Am. Rev. Respir. Dis. 140:1704-1711.

20. Goldstein, I. M. 1988. Agents that interfere with arachidonic acid metabolism. In Inflammation: Basic Principles and Clinical Correlates. J. I. Gallin, I. M. Goldstein, and R. Snyderman, editors. Raven Press, Ltd., New York. 935-946.

21. Persson, C. G. A. 1986. Hypothesis. Role of plasma exudation in asthmatic airways. Lancet. ii:1126-1129.

22. Majno, G., S. M. Shea, and M. Leventhal. 1969. Endothelial 
contraction induced by histamine-type mediators. J. Cell Biol. 42:647-672.

23. Borson, D. B., R. Corrales, S. Varsano, M. Gold, N. Viro, G. Caughey, J. Ramachandran, and J. A. Nadel. 1987. Enkephalinase inhibitors potentiate substance P-induced secretion of ${ }^{35} \mathrm{SO}_{4}$-macromolecules from ferret trachea. Exp. Lung Res. 12:21-36.

24. Sekizawa, K., J. Tamaoki, P. D. Graf, C. B. Basbaum, D. B. Borson, and J. A. Nadel. 1987. Enkephalinase inhibitor potentiates mammalian tachykinin-induced contraction in ferret trachea. J. Pharmacol. Exp. Ther. 243:1211-1217.

25. Umeno, E., D. M. McDonald, and J. A. Nadel. 1989. Fate of neutrophils that adhere to venules in neurogenic inflammation of the rat trachea and role of neutral endopeptidase: migration or detachment. Am. Rev. Respir. Dis. 139:A236.
26. Umeno, E., J. A. Nadel, H.-T. Huang, and D. M. McDonald. 1989. Inhibition of neutral endopeptidase potentiates neurogenic inflammation in the rat trachea. J. Appl. Physiol. 66:2647-2652.

27. Kohrogi, H., J. A. Nadel, B. Malfroy, C. Gorman, R. Bridenbaugh, J. S. Patton, and D. B. Borson. 1989. Recombinant human enkephalinase (neutral endopeptidase) prevents cough induced by tachykinins in awake guinea pigs. J. Clin. Invest. 84:781-786.

28. Rubinstein, I., I. Iwamoto, I. F. Ueki, D. B. Borson, and J. A. Nadel. 1990. Recombinant neutral endopeptidase attenuates substance P-induced plasma extravasation in the guinea pig skin. Int. Arch. Allergy Appl. Immunol. 91:232-238.

29. Borson, D. B., S. Jew, and D. C. Gruenert. 1989. Glucocorticoids increase expression of neutral endopeptidase in transformed human tracheal epithelial cells. Physiologist. 32:226. 